\title{
SERRIDONUS LINNAVUORI (HOMOPTERA, CICADELLIDAE, DELTOCEPHALINAE): DESCRIÇÕES DE TRÊS NOVAS ESPÉCIES ${ }^{1}$
}

\author{
Keti Maria Rocha Zanol ${ }^{2}$
}

\begin{abstract}
Serridonus linnavuori (Homoptera, Cicadellidae, DeltocepialiNAE): DESCRIPTIONS OF TIIREE NEW SPECIES. The genus Serridonus Linnavuori, 1959 is redescribed (type species: Serridonus longistylus Linnavuori, 1959) and three new species added: S. luridus sp.n., S. foersteri sp.n. and S. serratus sp.n., all from Brazil. KEY WORDS. Homoptera, Cicadellidae, Deltocephalinae, Serridonus
\end{abstract}

O material estudado pertence às seguintes instituições: Coleção de Entomologia Pe J.S. Moure, Universidade Federal do Paraná, Curitiba (DZUP), Museu de Zoologia da Universidade de São Paulo, São Paulo (MZSP) e California Academy of Science, San Francisco (CAS).

\section{Serridonus Linnavuori, 1959}

Serridonus Linnavuori, 1959: 181 Espécie-tipo: S. longistylus Linnavuori, 1959 (designação original). - Linnavuori \& DeLong, 1978: 129 (distribuição). - Cwikla \& Blocker, 1981: 172 (citação). Zanol \& Menezes, 1982: 42 (distribuição). - Oman et al., 1990: 251 (catálogo).

Cabeça. Coroa de comprimento uniforme.Região frontal intumescida e esculturada. Margem anterior esculturada. Região discal lisa com leves estrias longitudinais. Sutura coronal alcançando a metade do comprimento da coroa. Ocelos, na margem anterior, visíveis de cima. Distância ocelo-ocular menor que o diâmetro dos ocelos. Sutura frontoclipeal estendendo-se além dos ocelos. Sutura transclipeal arqueada. Anteclípeo mais largo no ápice; plano. Genas com reentrância abaixo dos olhos.

Pronoto mais estreito que a cabeça; superfície lisa; margens laterais carenadas e curtas. Tégminas sem falsas veias; com 2 células anteapicais. Margem costal com veias extranumerárias. Clavo com veias extranumerárias entre as anais e a sutura claval. Apêndice longo, ultrapassando $M 3+4$. Espinulação dos fềmures posteriores $2+2+1$; das tíbias anteriores $1+4$.

Genitália. Macho. Valva genital triangular. Placa subgenital triangular com ápice arredondado; macrocerdas dispostas em duas fileiras até a metade do comprimento da placa e unisseriadas até o ápice. Pígóforo com apêndices ventrais e dorsais. Estilos digitiformes, ultrapassando a metade do comprimento da placa subgenital. Conetivo com braços divergentes. Edeago simétrico, curvo, voltado para superfície dorsal; ápice bífido. Gonóporo na superfície ventral.

Fêmea. Placa subgenital com fenda mediana.

1) Contribuição número 961 do Departamento de Zoologia, Universidade Federal do Paraná.

2) Departamento de Zoologia, Universidade Federal do Paraná. Caixa Postal 19020, 81531-990 Curitiba, Paraná, Brasil. Bolsista do CNPq. 


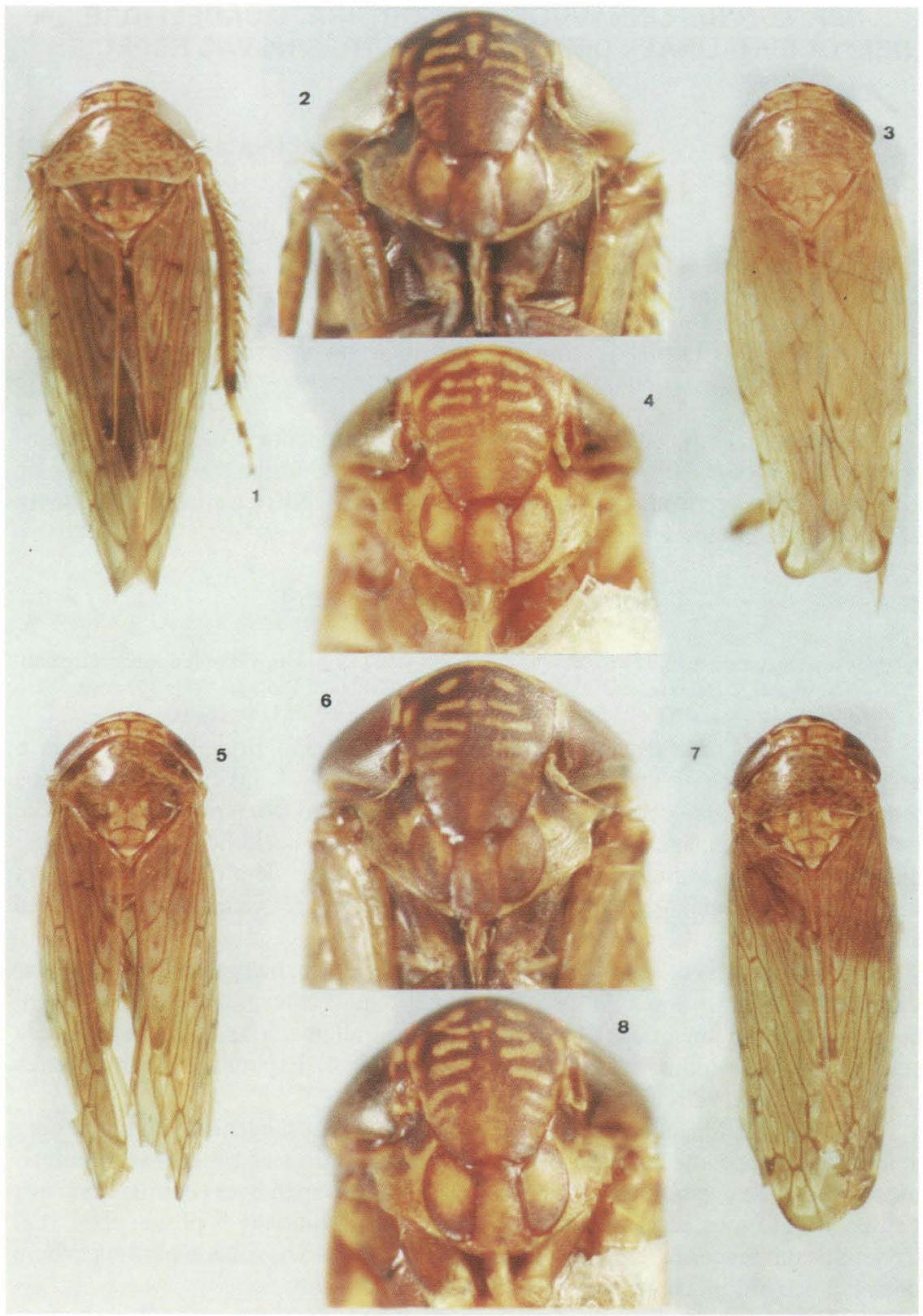

Figs 1-8. (1-2) Serridonus longistylus Linnavuori: (1) dorsal; (2) face. (3-4) Serridonus luridus sp.n.: (3) dorsal; (4) face. (5-6) Serridonus serratus sp.n.: (5) dorsal; (6) face. (7-8) Serridonus foersteri sp.n.: (7) dorsal; (8) face. 
Distribuição: Brasil, Bolivia, Paraguai, Argentina.

Espécies incluídas:

Serridonus longistylus Linnavuori, 1959 - Argentina, Paraguai, Bolivia, Brasil (Mato Grosso, Rondônia, São Paulo).

S. luridus sp.n. - Brasil (São Paulo).

S. serratus sp.n. - Brasil (Mato Grosso).

S. foersteri sp.n. - Brasil (Mato Grosso).

Serridonus longistylus Linnavuori, 1959

Figs 1-2, 9-14

Serridonus longistylus Linnavuori, 1959: 181-182 (descrição). - Linnavuori \& DeLong, 1978: 129. Zanol \& Menezes, 1982: 42 (distribuição).

Coloração geral marrom-clara. Coroa amarelada; margem anterior com quatro manchas e uma faixa transversa entre as suturas frontoclipeais marrom-escuras. Face marrom; frontoclípeo com arcos laterais amarelados; lora com áreas amareladas. Pronoto marrom-claro irrorado de marrom. Tégminas marrom-claras com manchas marrom-escuras e áreas esbranquiçadas nas células.

Genitália. Macho: pigóforo com um par de apêndices dorsais, voltados para a superfície ventral e para frente; borda interna serreada. Superfície ventral com dois pares de apêndices: um basal, tão longo quanto o pigóforo e espatulado, voltado para frente e o outro, mais apical, triangular. Estilos com ápice alargado e truncado.

Fêmea: sétimo esternito com fenda em forma de $\mathrm{V}$ invertido, ultrapassando a metade do comprimento da placa.

Comprimento total. Macho: $6 \mathrm{~mm}$; Fêmea: $6 \mathrm{~mm}$.

Material-tipo. Holótipo na coleção Rauno Linnavuori depositado no American Museum of Natural History, New York. Páratipo depositado no Hungarian National Museum, Budapest.

Material examinado. BrasiL, Mato Grosso: Cáceres, 13.XI.1984, 2 machos, C. Elias leg. Projeto Polonoroeste (DZUP, CAS); Barra do Tapirapé, 1.I.63, 1 fêmea, B. Malkin leg.; Rondônia: Pimenta Bueno, XI.1960, 1 macho, M. Alvarenga leg., (DZUP).

Variação intraespecífica. Em um exemplar macho (Cáceres) a veia transversa entre $1 \mathrm{~A}$ e a sutura é bifurcada e no exemplar macho (Pimenta Bueno) na tégmina direita observam-se duas transversas entre as anais e na esquerda a transversa entre $1 \mathrm{~A}$ e a sutura bifurcada. $\mathrm{O}$ apêndice triangular na superfície ventral do pigóforo, pode apresentar a borda externa serreada.

\section{Serridonus luridus sp.n.}

Figs 3-4, 15-19

Holótipo. Coloração geral amarelada. Genitália: pigóforo com um par de apêndices dorsais, voltados para dentro e para frente; borda interna serreada. Superfície ventral com dois pares de apêndices; o par basal espatulado, ultrapassando o ápice do pigóforo e o outro, mais apical, pequeno e triangular, ambos voltados para frente. Estilos com o ápice curvo para fora. 


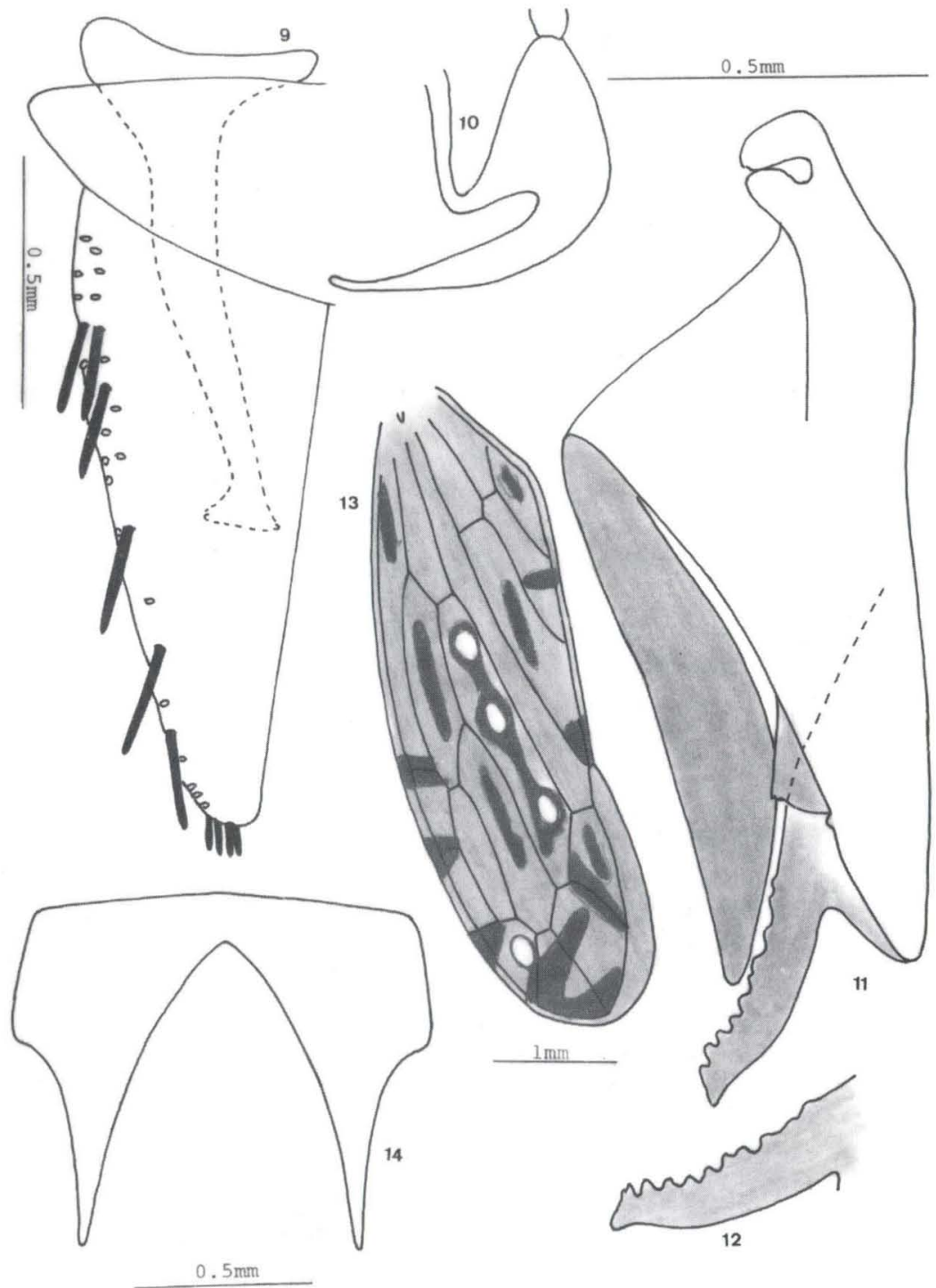

Figs 9-14. Serridonus longistylus Linnavuori. (9) Valva genital, placa subgenital e estilo; (10) edeago, lateral; (11) pigóforo, lateral; (12) apêndice dorsal, pigóforo; (13) tégmina; (14) sétimo esternito da fêmea.

Fêmea. Desconhecida.

Comprimento total. Macho: $5,80 \mathrm{~mm}$

Material examinado. Holótipo macho. Brasil, São Paulo: Rubinéia, 16.III.1972, M. Menezes leg. (DZUP). 


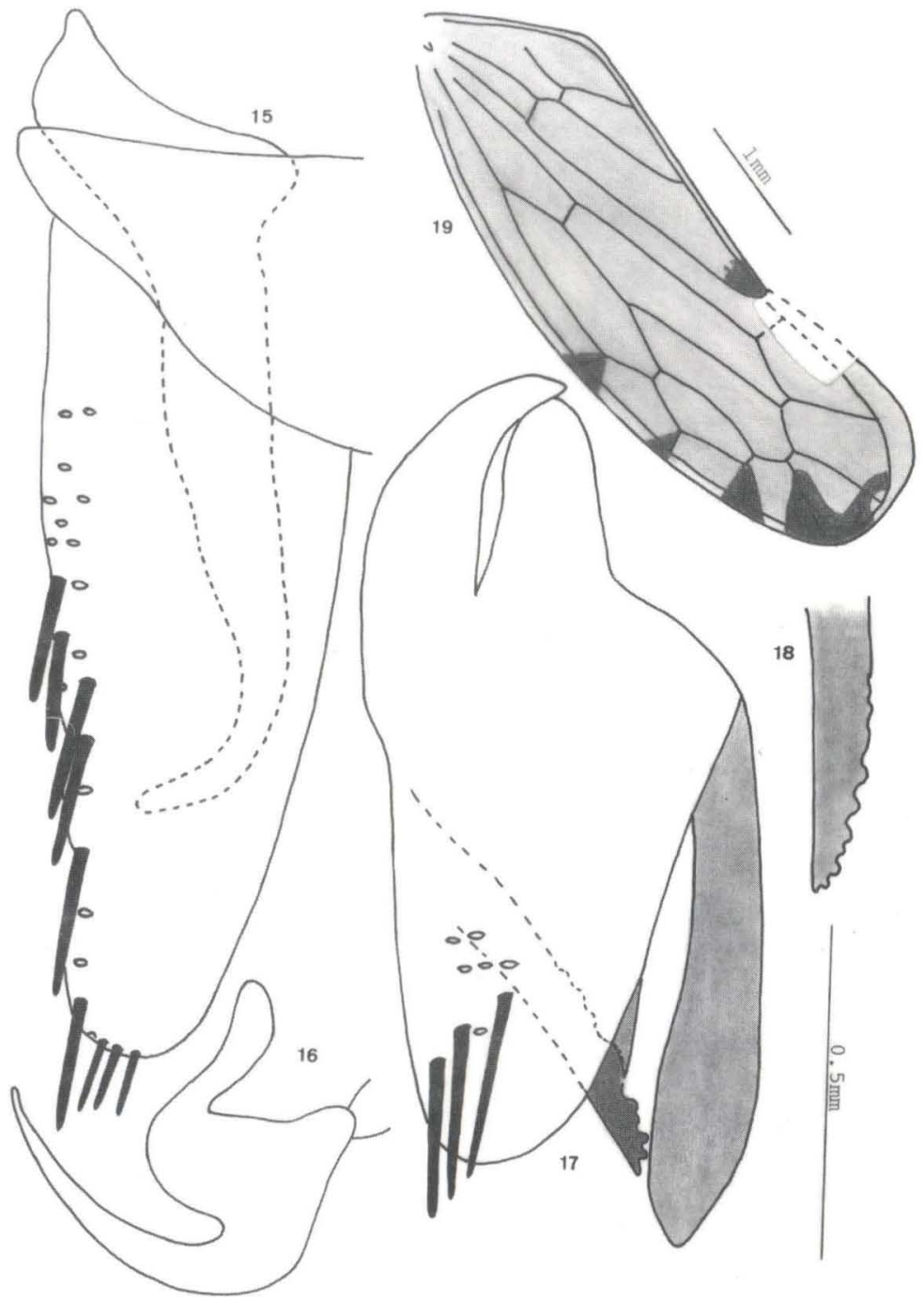

Figs 15-19. Serridonus luridus sp.n.. (15) Valva genital, placa subgenital e estilo; (16) edeago, lateral; (17) pigóforo, lateral; (18) apêndice dorsal, pigóforo; (19) tégmina.

Comentário. Serridonus luridus difere das demais espécies pela coloração amarelada, pela apófise do estilo que é curva para fora e pelos apêndices ventrais do pigóforo, o apical, pequeno e triangular e o basal, em vista ventral, com aspecto tortuoso.

O nome da espécie é devido a coloração amarelada. 


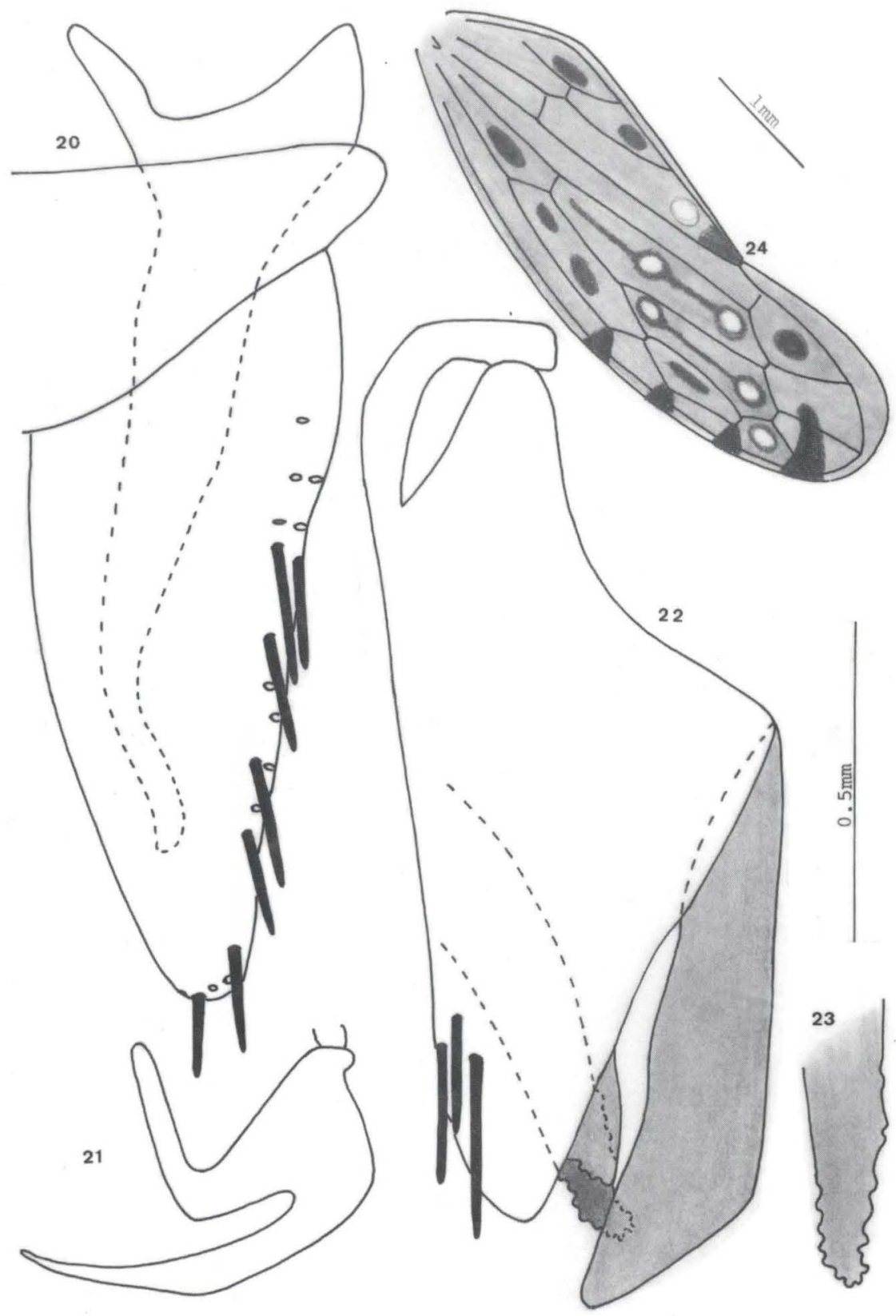

Figs 20-24. Serridonus serratus sp.n.. (20) valva genital, placa subgenital e estilo; (21) edeago, lateral; (22) pigóforo, lateral; (23) apêndice dorsal, pigóforo; (24) tégmina. 


\section{Serridonus serratus sp.n.}

Figs 5-6, 20-24

Holótipo. Externamente como S. longistylus. Genitália: pigóforo com um par de apêndices dorsais serreados, voltados para dentro e para frente. Superfície ventral com dois pares de apêndices, com o par basal espatulado ultrapassando o ápice do pigóforo e o par mais apical triangular com a margem externa serreada. Estilos com apófise sinuosa.

Fêmea. Desconhecida.

Comprimento total. Macho: $5,90 \mathrm{~mm}$.

Material examinado. Holótipo macho. Brasil, Mato Grosso: Cáceres, 1.XII.1984, C. Elias leg. Projeto Polonoroeste (DZUP).

Comentário. Esta espécie difere das demais por apresentar a apófise do estilo sinuosa, pelas bordas serreadas do apêndice dorsal do pigóforo e pelos apêndices ventrais do pigóforo: o basal fortemente espatulado e o apical com a margem externa serreada.

O nome da espécie é devida às bordas serreadas do apêndice dorsal e da margem externa do apêndice ventro-apical, do pigóforo.

\section{Serridonus foersteri sp.n.}

Figs $7-8,25-29$

Holótipo. Externamente como S. longistylus. Genitália: pigóforo com o par de apêndices dorsais, voltados para frente com a borda interna, serreada; superfície ventral com dois pares de apêndices, o par basal sinuoso, mais ou menos falciforme, tão longo quanto o pigóforo e o par mais apical sinuoso com a borda interna, na metade apical, serreada, e ambos voltados para frente. Estilos com o ápice curvo para dentro.

Fêmea. Desconhecida.

Comprimento total. Macho: $6,00 \mathrm{~mm}$.

Material examinado. Holótipo macho. Brasil, Mato Grosso: Barra do Tapirapé, X.1964, B. Malkin leg. (DZUP). Parátipo macho, Ibidem, 14.XII.1964 (MZSP).

Comentário. Esta espécie apresenta o mesmo padrão de coloração de $S$. longistylus e $S$. serratus, diferindo por apresentar a apófise do estilo curva para dentro e pelos apêndices ventrais do pigóforo.

Espécie dedicada ao Prof. Dr. Luis Amilton Foerster, Departamento de Zoologia, Universidade Federal do Paraná.

\section{REFERÊNCIAS BIBLIOGRÁFICAS}

CWIKLA, P. \& D.H. Blocker. 1981. Neotropical genera of Deltocephalinae not included in Linnavuori's 1959 keys. Bull. Ent. Soc. Amer. 27 (3): 170-178.

LINNAVUORI, R. 1959. Revision of the neotropical Deltocephalinae and some related subfamilies (Homoptera). Ann. Zool. Soc. Vanamo 20 (1): 1-370. 


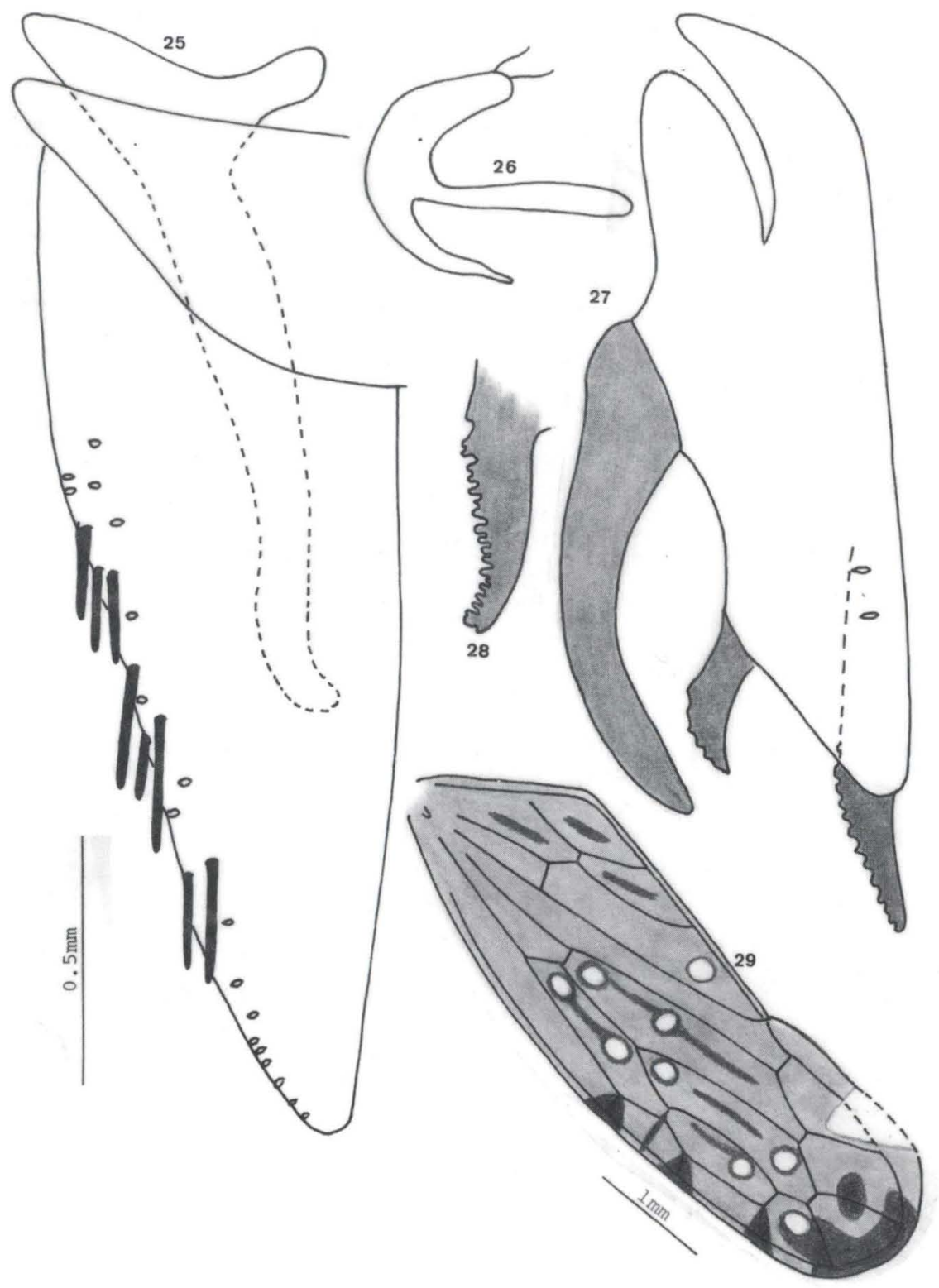

Figs 25-29. Serridonus foersteri sp.n.. (25) Valva genital, placa subgenital e estilo; (26) edeago, lateral; (27) pigóforo,lateral; (28) apêndice dorsal, pigóforo; (29) tégmina. 
Linnavuori, R. \& D.M. DeLong. 1978. Neotropical leaf hoppers of the Bahita group (Homoptera: Cicadellidae: Deltocephalinae). A contribution to the taxonomy. Brenesia 14-15: 109-169.

OMAN, P.W.; W.J. KNIGHT \& M.W. NiELSON. 1990. Leaf hoppers (Cicadellidae): A bibliography, generic check-list and index to the world literature 19561985. C.A.B. International, 386p.

ZANOL, K.M.R. \& M. MENEZES. 1982. Lista preliminar dos cicadelídeos (Homoptera: Cicadellidae) do Brasil. Iheringia, Sér. Zool., 61: 9-65.

Recebido em 17.X.1996; aceito em 03.IX.1997. 